ESJ Social Sciences

\title{
Evaluating Organisational Change and Employee Productivity in Nigeria: A Case Study of Union Bank, Plc
}

\author{
Patrick Ohunmah Igudia, PhD \\ Department of Business Administration, \\ Ambrose Alli University, Ekpoma
}

Doi:10.19044/esj.2021.v17n19p208

Submitted: 28 April 2021

Accepted: 16 June 2021

Published: 30 June 2021
Copyright 2021 Author(s)

Under Creative Commons BY-NC-ND

4.0 OPEN ACCESS

Cite As:

Igudia P.O. (2021). Evaluating Organisational Change and Employee Productivity in Nigeria: A Case Study of Union Bank, Plc.

European Scientific Journal, ESJ, 17(19), 208. https://doi.org/10.19044/esj.2021.v17n19p208

\section{Abstract}

This study examined the effects of organisational change on employee productivity in the banking sector in Nigeria. Following a comprehensive literature review, the study identified technological, cultural, employee attitude to change, leadership, and change in customers' taste as the change strategies that can facilitate competitive advantage and attainment of set organisational goals. The primary data collection method was adopted employing questionnaire strategy. 102 respondents were selected as sample size. The study used the multiple regression statistical analysis through SPSS statistical package version 25 for analysis. The overall results revealed that organisational change has a positively significant impact on employee productivity. To this effect, technological, leadership, attitudinal and cultural changes in that order highly impact employee productivity in Union Bank even though they were rarely used to implement change. As a result, Union bank is advised to embrace convergent change management so as to be better equipped to maintain excellence in productivity and overcome external challenges such as competition. On the contrary, changes especially in customer taste do not influence the productivity of employees, perhaps due to the nature of their business operations (service). The study recommends among others that while implementing firm's improvement strategies, Union Bank managers should look at the organisation's technological change models, cultural change, employees' attitude to change, and leadership change against their primary competitors. 
Keywords: Organisational change, employee productivity, banking sector, change management

\section{Introduction}

Nothing is static. The only thing permanent in life is change. The world is changing and so does the business environment. The rate of change experienced by business organisations seems to be increasing more and more especially since the last five decades. This is as a result of advancement in information and communications technology (ICT), globalisation, spread of democracy around the world (including hitherto fascist and communist countries like Russia) and liberalisation of economies across the globe. Recently, the COVID-19 pandemic broke out altering both the social and economic environments worldwide. While the former impressively improved the ways businesses are conducted globally, the latter brought about closure and restrictions to business operations worldwide. This has also led to increased business competition, and consequently improved the value of companies. The new phenomena require that a company needs to manage its organisational changes as they occur. Many organisations have confirmed frustrations given the cost and uncertainty associated with change (Korir \& Mukolive, 2012). However, some organisations have claimed significant advantages arising from their ability to apply extensive change management to their old ways of doing things (Kim, 2018). An insight of organisations that have benefited from the introduction of organisational change was given by Martins (2011) in his study when he reported that the efficiency of US production employees improved by $4.5 \%$ per year from the 1990 figures as a result of the efficient management of the dynamics of change in the industrial economy.

When there are changes in the internal and/or external environments of an organisation, such changes usually have direct or indirect effects on the employee's productivity. Several factors such as rapid and unpredictable change in customer attitudes and change in information technology can make the introduction of organisational change inevitable. Organisations that can manage such changes are likely to survive long-term (Olajide, 2014). Organisations that are versatile and are able to predict the future of the industry are more likely to deal with the complexities of organisational change.

The Union Bank of Nigeria, Plc (UBN) belongs to the banking sector whose services have so far remained one of the foremost in the country. The margin of survival or the ability to remain an industry leader has since become slimmer as competition becomes more furious in the industry especially with the rise of new generation banks. There are numerous new services and product categories that have made the bank (UBN) to constantly innovate. As 
one of the known industry giants, UBN cannot afford to sit back and rest on its oars or rely on its previous success stories. As of today, there are 22 functional commercial banks in Nigeria. Going by this number, no bank in Nigeria worth its salt can afford to fold its hands and look on. Managers of banks in Nigeria are continually on each other's throats trying to outwit one another by devising new service delivery strategies while at the same time minimising the cost of change implementation. It has been suggested that many of the banks that went under during the 2001 bank consolidation exercise may have done so because they couldn't effectively manage the change that occurred within the industry during the period. The poor survival rate indicates lack of a fundamentally valid framework of how to implement and manage organisational change. This is the crux of this study.

Literature is sparse on the impact of organisational change on employee productivity in the banking industry in Nigeria. It is not clear from literature if there has been any systematically developed framework on how to implement and manage organisational change in banks whether in Nigeria or anywhere else in the world. Therefore, this study attempts to add to the debate relating to organisational change and employees' productivity and systematically develop a framework for doing so thereby expanding and filling both theoretical and practical knowledge gulf. In this study, technological change, cultural change, attitudinal change, leadership change, and change in customer taste are used as proxies for organisational change. In this light, this study aims to statistically evaluate the impact of organisational change on employee productivity in the banking industry in Nigeria with a focus on Union Bank Nigeria, Plc (UBN). Given this backdrop, the study posses the following research questions:

1. What is the impact of technological change on employee productivity in the Banking sector of the Nigerian economy?

2. What is the relationship between cultural change and employee productivity in the Nigerian banking sector?

3. What is the impact of employee attitude on employee productivity in the Nigerian banking sector?

4. What is the impact of leadership change on employee productivity in the Nigerian banking sector?

5. What is the impact of change in customer taste on employee productivity in the Nigerian banking sector?

To provide answers to these research questions and execute the research objective, the paper develops five hypotheses. 


\section{Literature Review}

\subsection{Conceptual and Theoretical Review}

Literally, change means to transform or alter something so as to become different from the original state. Such change can be a deliberate act of management within the organisation or externally originated for the organisation (Kwizera et al., 2019), in which case, it will be beyond the control of the organisation. The concept of organisational change means a business change such that executive leaders, managers and frontline employers work in concert to successfully implement the needed process, technology or organisational changes (Korir \& Mukolive, 2012). While Moran and Brighton (2011) defined organisational change as the process of continually renewing an organisation's direction, structure and capabilities to serve the ever changing needs of both the external and internal customers, Burnes (2004) asserts that change is an ever present feature of an organisational life, both at the operational and strategic levels.

The understanding of organisational change concept can be summarised into two discrete trajectories: one, as a task of managing change (from a reactive or proactive viewpoint) (Balogun \& Hailey, 2004), and two as an area of professional practice (with considerable variation in competency and skill levels among practitioners) (Balogun \& Hailey, 2004). Explaining the concept of organisational change from these two trajectories involves at least three meanings (Allen \& Herbert, 2002). First, it can refer to the making of changes from within the organisation in a planned or systematic manner with the aim of effectively implementing new methods or technological innovations in the organisation. Such changes are usually internally created and are therefore within the control of the organisation. The second meaning involves a reaction or response to changes that occur in the organisation but over which the organisation has little or no control (e.g. technology, national legislation, social and political upheavals, the actions of competitors, unstable economic tides and so on). Such changes can be managed by an organisation either reactively or proactively (Warren et al., 2009).

Management can enforce a change only with the cooperation of its workers. To accept a change means that the status-quo has to be altered (Lewin, 1948). The implementation of the changes that occur in organisations requires certain necessary modifications to the nature and configuration of organisational resources (economic, human, technological, information, and administrative). To do so the organisation should have a clear strategic plan to manage all potential role conflicts that arises and minimise the resistance to change from within the employees of the organisation. Changes implemented in organisations are usually the outcome of a decision-making process which the firm designs with anticipation (Rajagopalan \& Spreitzer, 1996) in order to accomplish a competitive advantage in the industry (Burgelman, 1991). The 
accomplishment of an extremely competitive position in the industry rests squarely on the top management team which usually does not only decide the scope of change to be implemented in the future but also decides the type of change to be identified and designed. However, the upper managers work on the process of strategy formulation (Khatoon \& Farooq, 2016).

This study is undertaken through the lenses of the theory of "force field analysis" propounded by Kurt Lewin in 1948. The theory postulates that there are two categories of forces - driving forces and restraining forces - in any organisation. One of the forces involves some employees who will accept organisational change and the other group who will reject or resist it. The driving forces make organisational change attractive to employees while the restraining forces labour to maintain the status quo or keep things as they are. This explains why people either easily accept organisational change or persistently resist it. Thus, effective organisational change management therefore requires that management adds some conditions favourable to the change being introduced and reduce the resisting forces (Connelly, 2017). The task of managing organisational change includes managing its impact on people. For management to achieve successful change in an organisation it needs to strengthen the driving forces and weaken the restraining forces (Lewin, 1948).

It is the assumption of this study that both the management team and the employees of Union Bank of Nigeria (UBN) Plc. unanimously accepted the need to introduce certain necessary changes. But the next logical question is what would be the impact of such changes on the employees' productivity? This has led to the undertaken of a comprehensive literature review in relation to the impact of organisational change on employees' productivity.

\subsection{Meaning of Employee Productivity}

Productivity can be described using various measures such as the efficiency and effectiveness of production. Literally, productivity describes the quality, state, or fact of being able to generate, create, enhance, or bring forth goods and services. It may also mean the production power, profitability, and generation of output. In Japan, productivity is defined as the ability or capacity to maximise the use of physical resources, human resources, and other factors at lower production costs, increase market expansion, increase employment and, a rise in living standards.

The main focus of productivity is the human resource. The human resource is the driving force of productivity. It is the most important element needed to achieve the desired goals and objectives of any organisation as it is the only factor that gives effect to organisational change and guarantees the survival of the organisation using other resources. Accordingly, motivation, creativity, innovation, competitiveness, activity cost reduction, the 
improvement in the quality of activities, work time reduction, job satisfaction, and the spirit to achieve goals positively affect the level of productivity (Tavakolia, 2010). Conversely, downsizing, mergers, innovations and restructuring of organisations usually decrease employee's productivity (Khosa et al, 2016).

Every organisation sets its own objectives (Diener \& Seligman, 2004). Organisational objectives are usually achieved by the use of organisational resources. While the other resources are important on their own, it is the human resource that coordinates all other factors for the accomplishment of organisational goals. Notwithstanding the nature of tasks performed, all the activities are by design inter-related to achieve the set organisational targets (Ho, 2008). The separate performance by the individual employee when properly harnessed yields the best output for the organisation with great impact on the total production, sales, profit, progress and market position of the company in the market. Various factors like skills, training, motivation, dedication, welfare, management policies, fringe benefits, salary and packages, promotion, communication etc. are some of the incentives that encourage employees to work sincerely and give their best.

According to some authors, service firms like the banking sector invest more on their work force in order to maintain long term relationship with them and increase their performance and job satisfaction (Karatepe et al, 2006). With such an effort guided by an appropriate motivation, a service company such as the UBN. Plc may grab the opportunities to become the industry leader (Khosa et al, 2016; Ho, 2008). Therefore, paucity of employee productivity at UBN is likely to be surmounted by appropriately introducing certain changes such as technological innovation, the right organisational culture, appropriate employee attitude/tolerance to change, effective leadership, and change in customer's taste in its work processes.

\subsection{Review of Empirical Literature}

\subsubsection{Organisational Change and Employee Productivity}

Previous studies (see for example: Nwinyokpugi, 2018; Obondo, 2004; Ejuu, 2003) have investigated productivity phenomenon and how it has been affected by different variables including leadership change, motivation, etc. Several studies reported that the lack of corporate approach in the process of data collection is critical to the sustainability of change processes especially in large work environments such as the Union bank. Mullins (2010), for example, has argued that factors such as uncertain economic and political conditions, change in social attitudes, fierce competition, takeovers, acquisitions, technological developments and governmental interventions create an increasingly volatile environment for certain kinds of organisations 
and consequently inhibit the effective performance and productivity of employees.

Kwizera, et al (2019) in their study of the effect of organisational change on employee performance among selected commercial banks in Bujumbura, Burundi concluded that organisational change has a significant effect on employee performance with structural and technological changes causing the greatest impacts. Results of several studies that investigated the impact of organisational change on employee productivity are not substantially different depending on the variables investigated and context studied. For example, results of Karanja (2015)'s study on the effects of organisational change on employee performance of postal corporation of Kenya indicated that there is an overall positive relationship revealing however that technology had the greatest influence. However, the nature of the context as a public organisation that provides some internship programme that generates several job opportunities could explain the result (Kwizera, et al., 2019). Joseph Isern and Caroline Pung, (a director and a consultant respectively at McKinsey and company, an online survey institute), investigated a five year data of 1536 companies. In the study, they submitted that $38 \%$ of the organisations surveyed reported that their recently introduced organisational change had a "completely" or "mostly" successful impact on their employee performance (Isern \& Pung, 2007). But such performance can only come through if management has a clear understanding of the organisation's capabilities and readiness to change among other things. Although transformations tend to feel chaotic by their dynamic nature, it is vital that organisational leaders take a disciplined approach to each of these requirements.

Similarly, Wanza and Nkuraru (2016) found in their study that a strong organisational culture, a variable of organisational change, creates synergy and drive that encourage teamwork and enhance employee performance. They argued that structural changes, change in leadership, technological innovation and change in organisational culture positively impact the performance of employees. Also, Ahmed et al. (2013) reported a positive impact of organisational change on employee performance in the banking sector of Pakistan. Although the study was particularly on the banking sector of Pakistan, they however suggested that subsequent research should be extended to the other sectors of the Pakistan's economy. Similar studies on leadership and compensation in the corporate sector of Pakistan (Khan \& Jabbar, 2013), attitude and practice in Maruti Suzuki (Kansal \& Singh, 2016), technological changes, organisational leadership, structure and culture in the educational sector (Wanza \& Nkuraru, 2016) and several others indicated a positive impact between organisational change and employee productivity at varying degrees. 
Following comprehensive review of literature, this paper develops a framework (see figure 1) for organisational change and employee productivity and specifies some hypotheses to be tested based on claims by previous authors. The intention is to determine if the expected findings would corroborate the findings of previous authors.

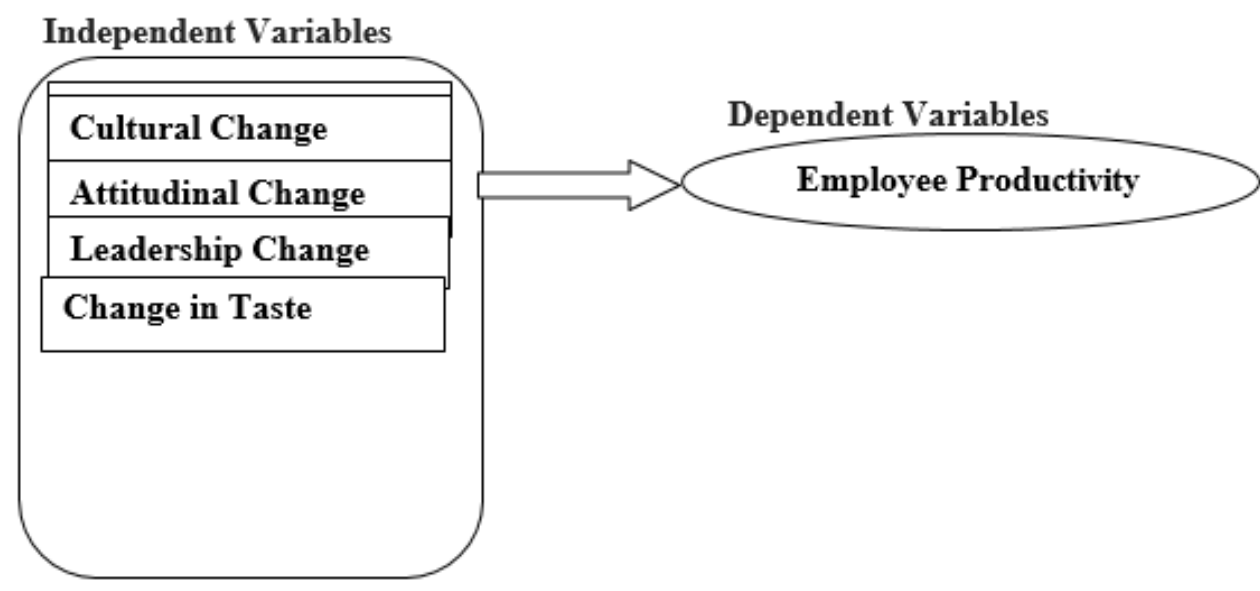

Figure 1: Organisational Change framework of a typical Bank in Nigeria

\subsubsection{Technological Change and Employee Productivity}

Technology has become a very valuable asset to any organisation in today's business environment. But the issue is the ability to identify the most appropriate technology for your organisation. Because, the right technology can vastly improve a company's overall efficiency and performance in the market, as well as improve employee productivity, communication, collaboration, morale and engagement company-wide (Coppersmith, 2019). One of the new technologies that is gaining growing popularity and has assumed a strategic and practical position in organisations is information and communication technology (ICT).

There is evidence that new technologies can improve the quality of care processes by enhancing communication, standardising processes, and enhancing workflow, especially when used in addition to existing care rather than as a substitution (Smith, 2007). ICT can support and drive innovative work practices and research in the banking sector (Westbrook et al., 2009). The context in which new technology is implemented determines its impact on staff and ultimately its sustainability (Peterson et al. 2014). The incorporation of ICT into the workplace has had a major impact on human resource utilisation especially in financial services (Anvari, 2007). Following from the results of the referred empirical studies, this study postulates that:

$\mathrm{H}_{0} 1$ : There is no positive relationship between technological change and employee productivity in $U B N$. 


\subsubsection{Organisational Culture and Employee Productivity}

Interest in organisational culture has raised the arguments about what culture is, and how it should be analysed (Schein, 2004). Hence, it is said that culture is a subjective idea used in a broad sense with changing contextual symbolism (Martins, 2011). However, culture has been defined as a mixture of values, set of beliefs, communications and explanation of behaviour that provides guidance to people (Awadh \& Saad, 2013). Organisational culture comprises the unwritten customs, behaviours and beliefs that determine the rules for decision-making, structure and power (Wambugu, 2014). Despite the variations, researchers recognise that the idea of business culture represents the distributed principles, actual presumptions, and behavioural objectives that regulate decision-making in an organisation (Cameron \& Quinn, 2011). The productivity of employees following the established work patterns, regulations, values, and guidelines contributes in part to the establishment of strong organisational culture (Wanza \& Nkuraru, 2016; Denison, 2004).

There has been several empirical research on the effect of organisational culture on employee productivity. Results of all the previous research efforts generally indicate that there is a positive relationship between the two. For instance, Baca and Claudia (2005) found that norms, a dimension of organisational culture, positively impacts organisational performance through increased profitability. Also, value and norms have been tested and found to positively impact organisational productivity (Awadh \& Saad, 2013). Their study reported that with cordial relationship amongst employees, an organisation can achieve competitive advantage; a proxy for organisational performance. Wambugu (2014) investigated the influence of organisation values, climate, leadership styles and work processes on employee's performance in a privately owned firm in Kenya. The overall result indicated that there exists a positive relationship between organisational value (a proxy for culture) and employee performance even though there was a diverse variation in the levels of impact amongst the different variables with work processes and systems having more effect on employee's performance (Wanza \& Nkuraru, 2016). Given the results found in literature, this study postulates that:

$\mathrm{H}_{0} 2$ : There is no positive relationship between cultural change and employee productivity in $U B N$.

\subsubsection{Employee Attitude to Change and Employee Productivity}

Attitude refers to the way people think and feel about someone or something. It is a thought line which affects someone's behaviour towards others or things. Not every employee in an organisation will react to organisational change in the same manner and the same temperament. While 
some will easily accept change because they believe it will favour their career path and skills (Isern \& Pung, 2007), others will show resentment because they believe such change will not support their course. Those who want the status quo to remain can express their anxiety by resisting new skills and knowledge acquisition needed to implement the new change, and thus resort to any methods possible to frustrate its implementation (Lin \& Liu, 2012). Whether positive or negative, the attitude of an employee affects how such employee would approach their jobs because attitudes do have a ripple effect on those around them. Generally, a positive attitude has a positive impact on productivity while the reverse is also true. A worker with good attitude has a better performance index compared to that with poor attitude (Lines, 2005; Amenakis \& Bedeian, 2001).

Literature is replete with evidence of the effect of employee's attitude towards change on employee productivity. Indeed, researchers (see for example: Holt et al., 2007; Mento et al., 2002; Armenakis et al., 1999; Kotter, 1995; Sashkin \& Burke, 1987) are in agreement on the significant role positive attitude of employees plays to obtain a successful change implementation. Based on the findings of previous studies, the present study hypotheses that:

$\mathrm{H}_{0} 3$ : There is no positive relationship between employee attitude to change and employee productivity in $U B N$.

\subsubsection{Leadership Change and Employee Productivity}

Generally, a leader is that person whose behaviour guides others, and as a role model, people look up the leader for achieving their own goals (Khosa et al, 2015). Leadership as a function of a leader is the act of influencing employees towards the attainment of an organisational goal (Adekanmbi \& Ukpere, 2020). A leader is one who has the power of reward and punishment and can award such appropriately and fairly to his employees. Leaders can also motivate their employees towards task achievement, giving incentives and moral support so that employees can put more effort into their work (Webb, 2007).

Burnes (1978) was the one who developed the initial ideas of transformational and transactional leadership in the political context (Khatoon $\&$ Farooq, 2016). However, Bass (1985) refined those concepts and introduced them into the organisational context. Transformational leaders get involved in recognising the need for a change, create a new vision, and then institutionalise such a change (Tichy \& Devanna, 1990). Studies on leadership identified charismatic and visionary leaderships as other variants of leadership (House, et al., 1991). Notwithstanding the type of leadership, they all share common characteristics and perspectives such as articulating a vision, fostering acceptance of group goals, and providing individualised support. Every 
successful and effective leader changes the basic values, beliefs, and attitudes of followers such that they are willing to perform beyond the minimum levels specified by the organisation (Podsakoff et al., 1996). Therefore, the level of success in the implementation of organisational change and the level of performance of employees in organisations depend, to a large extent, on the commitment of the leadership (Khosa et al, 2015). In short, a leader is that individual in an organisation who has the ability to influence employees to work efficiently and achieve organisational goals (Wang, et al 2005).

To implement organisational change, successful organisational leaders should combine both the formal and informal organisational structure as their principal instrument of action (Khatoon \& Farooq, 2016) as well as pay attention to organisational culture and provide a new basis for cohesion (Hirschhorn, 2000; Almaraz, 1994). Given the results of past studies, this study hypotheses that:

$\mathrm{H}_{0} 4$ : There is no positive relationship between leadership change and employee productivity in UBN.

\subsubsection{Change in Customer Taste and Employee Productivity}

Beginning from Canada, Laroche et al. (1986) and Constantine et al. (2006) separately conducted different surveys and found that speed of services, and factors relating to the competence and friendliness of bank personnel and convenience of location were the major factors which consumers perceive as important in their selection of a bank. Zineldin (2005) conducted a survey of 19 potential factors which customers consider as important in the selection of a bank. These factors include reputation, recommendation by others, interesting advertisement, convenience of location, opening hours and high technological services. The study revealed that friendliness and helpfulness of personnel, accuracy in account/transaction management, and availability of loans and provision of services were the most important factors. In the same vein, Irfan et al (2012) undertook a study that focused on finding out the main attributes that determine the customer's choice of bank for supplying mortgage products. The results indicated that the choice of customers for a mortgage product depends on all the independent variables like quality of services, cost of mortgage product, confidence level of customers as built by the bank in addition to the perceived convenience of the customers.

Omo (2011) investigated the determinants of banks selection criteria by banking and business customers in Nigeria and to determine the determinants of bank selection choices in Nigeria. The findings of the study revealed that the safety of funds and the availability of technology based service(s) are the major reasons for customers' choice of banks. Ulengin 
(1998) indicated that customers in developing nations are more interested in the functional quality of financial services than the technical quality dimension. The study reported that as there were no big differences among financial products offered by banks and the quality of financial products offered by banks are much beyond expectations of the customers, delivery channels and customer relations gain importance in staff productivity. The study concluded that, on an average, respondents of the survey prefer the extended customer loyalty programmes, the continuous information flow from the bank, the offsite ATMs, the minimum waiting time in the branches and a simplified application form for all accounts.

Colgage and Hedge (2001) conducted a study by investigating the problems that influence both switching behaviour and complaints made by bank customers prior to exit in order to provide a more comprehensive understanding of the process of switching retail banking services. They concluded that the most important customer taste selection criteria are convenience, bank reputations, quality of products and services, interest rates and fees, education and personnel contacts, facilities, branch environment, services and after service satisfaction. Their research on bank customers of Greece showed that bank selection criteria like location, convenience, quality of service (attention to the customer, personalised services, no queues) seem to influence the staff productivity. Phuong and Har (2000) undertook a study of customers' taste decisions in Singapore using the analytical hierarchy process (AHP) through a study of banking preferences of college students. The findings indicated that the most important criteria affecting such decisions are higher interest rate for saving, convenient location and overall quality of service. They are followed by the availability of self bank facilities, charges on services provided by banks, low interest rate on loans, long operating hours, availability of student privileges and recommendations by friends and parents specifically. Based on the findings of previous studies as found in literature, this paper postulates that:

$\mathrm{H}_{0} 5$ : There is no positive relationship between change in customer taste and employee productivity in UBN

3. Research Methodology

Organisational change factors are the independent variables while employee performance is the dependent variable. In this research paper, nominal and Likert scales were used in the questionnaire (Khosa1 et al, 2015). The Nominal scale shows the demographic profile of respondents while the Likert scale measures the impact of organisational change on employee's productivity in the banking sector in Nigeria. While the population comprises all the employees of the 22 commercial banks in Nigeria, the employees of 
Union Bank of Nigeria (UBN) plc totalling 2,322 form our sample frame. To achieve an appropriate sample size (actual sample size) in order to reduce the effect of non-response, the study applied the Saunders et al (2007) formula:

$x_{a}=\frac{x^{*} 100}{r_{r} \%}$

Where:

$x_{a}=$ the actual sample size

$x=$ adjustable minimum sample size

$r_{r} \%=$ estimated response rate expressed as a percentage

Taking 322 as the adjusted minimum sample size given that the population is approximately 2,322 employees at a 5\% level of certainty (Saunders et al, 2007), the actual sample size of this study can be calculated as:

$x_{a}=\frac{322 \times 100}{95}=339$

The sample size chosen for this research paper is 339 employees of UBN. 339 copies of questionnaire were distributed among 339 employees selected using the simple random sampling style. However, only 182 out of the 238 copies of the questionnaire retrieved from respondents were usable. The data gathered from the questionnaire were entered into SPSS version 25 to compute the regression analysis. The test re-test reliability test was carried out on the research instrument. The questionnaire was presented to colleagues who made necessary suggestions, corrections and amendments. The final copy that was eventually distributed was confirmed to have content validity and was also found reliable as shown in table 1 wherein all items recorded higher than 0.6 Cronbach's alpha as recommended by Gliem \& Gliem (2003).

Table 1: Test of Instrument Reliability

\begin{tabular}{lll}
\hline Variables & Dimensions/Measures & Cronbach's Coefficients \\
\hline Organisational Change & Technological Change & .754 (4 indicators) \\
& Cultural Change & .763 (3 indicators) \\
& Attitude to Change & .842 (2 indicators) \\
& Leadership Change & .772 (4 indicators) \\
& Customer Taste Change & $.728(4$ indicators $)$ \\
Employee Productivity & Task Accomplishment & .801 (2 indicators) \\
& Increased Output & $.912(2$ indicators) \\
\hline
\end{tabular}

Source: Survey data, 2020 


\subsection{Model Specification}

The multiple linear regression method was used to analyse the data specified as follows.

$$
\text { EmPer }=f(\mathrm{OrCh})
$$

Where:

EmPro = Employee Productivity;

OrCh = Organisational Change

But,

$$
\text { OrCh }=f(\text { Technological,Cultural, Attitude, Leadership,CustomerTaste })
$$

Thus,

$$
\text { EmPer }=f(\text { Technological,Cultural,Attitude,Leadership,CustomerTaste })
$$

Where:

Technological Change $=$ TechCh;

Cultural Change $=\mathrm{CulCh}$;

Attitude to Change $=$ AttCh;

Leadership Change $=$ LeadCh;

Customer Change in Taste $=$ CusTasteCh

Therefore,

$$
\begin{aligned}
& \text { EmPer }=f(\text { TechCh,CulCh, AttCh, LeadCh,CusTasteCh }) \\
& \text { EmPer }=f(\text { TechCh }+ \text { CulCh }+ \text { AttCh }+ \text { LeadCh }+ \text { CusTasteCh }+\mu)
\end{aligned}
$$

Transforming equation (3) into a proper linear regression equation, we have

EmPer $=a_{0}+a_{1}$ TechCh $+a_{2}$ CulCh $+a_{3}$ AttCh $+a_{4}$ LeadCh $+a_{5}$ CusTasteCh $+\mu$

Where: $\mathrm{a}_{1} \ldots \mathrm{a}_{5}$ are the regression coefficients and $\mu=$ stochastic error term

\section{Result of the Test of Hypotheses and Discussions}

\subsection{Result of the Test of Hypotheses}

As earlier specified, hypotheses were tested using the SPSS version 25 and the result is depicted in table 1.

\begin{tabular}{clccccccc}
\hline & Variables & & $\mathbf{1}$ & $\mathbf{2}$ & $\mathbf{3}$ & $\mathbf{4}$ & $\mathbf{5}$ & $\mathbf{6}$ \\
\hline 1. & TechCh & 1 & & & & & \\
2. & CulCh & 0.671 & 1 & & & & \\
3. & AttCh & 0.565 & 0.705 & 1 & & & \\
4. & LeadCh & 0.608 & 0.694 & 0.698 & 1 & & \\
5. & CusTasteCh & 0.563 & 0.560 & 0.421 & 0.481 & 1 & \\
6. & EmPro & 0.648 & 0.539 & 0.498 & 0.623 & -0.759 & 1 \\
\hline \multicolumn{7}{l}{ Table 2: Results of the Hypotheses Test conducted with SPSS version 25 }
\end{tabular}




\subsection{Discussions}

The relationship between technology and employee productivity shows that $\mathrm{p}$-value is 0.000 which is less than the $\mathrm{p}$-value $(\mathrm{p}<0.001)$. It shows that $\mathrm{H}_{0}$ is rejected and $\mathrm{H}_{1}$ is accepted. Therefore, there is a strong positive relationship between technological change and employee productivity. The Pearson correlation analysis shows the ( $\mathrm{r}$ value) is 0.648 or approximately $65 \%$, which is within the range of 0.3-0.7 indicating a more than average effect. As a result, we conclude that there is a positive impact of technological change on employee productivity. Thus, to embrace a new technology in the operations and service delivery of bank services ultimately increases employees' productivity. Also, the relationship between cultural change and employee productivity is positive at 0.539 (approximately 54\%) indicating more than average influence. The impact of employee attitude to change and employee productivity is positive at 0.498 or approximately $50 \%$ indicating a moderate influence. Leadership change also showed a positive relationship with employee productivity. The correlation analysis shows that (r-value) is $0.623(62.3 \%)$ showing that leadership has a high effect on employee's productivity. A good and effective leadership will show capacity and ability to influence even those with negative tendencies toward change (Drucker, 2003). The table also shows that though there is a high impact of change in customer taste on employee productivity, the relationship is negative at $\mathrm{p}>$ 0.01 indicating that the higher or more frequently there is a change in customer's taste, the lower the level of employees' productivity. Culture is shown in the result to have a statistically significant impact on employee productivity at Union Bank, Plc. with r-value at 0.539 indicating a 54\% positive effect. Thus, with a one unit change in culture, there is likely to be a $54 \%$ change in worker's productivity. As shown in table 2, technological change has the greatest positive impact on workers' productivity at Union Bank, Plc and therefore, management should focus more on developing its technological possibilities. On the other hand, customer taste has the greatest negative impact. The implication is that management must ensure that it monitors consistently what the people want and adhere strictly to their marketing concept philosophy in addition to relationship marketing as it is presently doing.

\section{Conclusion and Recommendations \\ 5.1. Conclusion}

In this research paper, an investigation of organisational change towards employee productivity in the banking sector of Nigeria was conducted. The study explored the relationship of employee productivity and some selected variables used as proxies for organisational change. These include: technology, organisational culture, employee's attitude to change, 
leadership, and change in customer's taste. The results of the statistical analysis revealed that the strongest impactful factor on employee productivity in the Union Bank operations is the technological change while the lowest influential factor affecting the employee productivity in Union Bank is change in customer's taste probably as a result of the nature of banking operations. Thus, it goes without saying that understanding the factors that impact employees' productivity is the first step and a sure way to not only understand how to improve employees' productivity but it will also enable the manager to strategically develop ways to enhance employees' level of productivity.

One of the limitations of this study is that we cannot generalise our results to cover the entire banking industry in Nigeria because our scope of investigation was limited to the Union bank Plc. However, if all 22 commercial banks in Nigeria have the same characteristics as the Union bank and share the same measurement parameters, most of the results obtained for Union bank may be true for others. Researchers are advised to increase the number or choose all 22 commercial banks for investigation or possibly select other sectors of the Nigerian economy with increased sample size. This will likely increase the validity and generalisability of the research findings as it relates to the impact of organisational change on employee productivity.

\subsection{Recommendations}

This study has exposed the implications of change on employee productivity, one of which is that it helps organisations to obtain total commitment of all the employees to work together in order to enhance work output and overall staff productivity. But to achieve this, management should perform its responsibility to ensure that employees are not only properly selected and trained but should also be informed that they can be responsible for achieving the desired organisational results (Drucker, 2003).

In view of the findings, this study recommends that:

- Managers should evaluate company actions and procedures to figure out methods to improve technological needs, cultural change, employee attitudes, leadership change and change in customer taste.

- Managers should have the grand strategy of discovering methods they can use to increase the needed change that will enable them to become competitive or even become industry leaders just as the Union Bank.

- Managers should develop modalities for evaluating service delivery procedures that will enable them to spot areas where they can improve their functions and eliminate redundancies among management and employees. This could lead to automating procedures, improving facilities, applying technologies, and exercising workers freedom. 


\section{References:}

1. Adekanmbi, F.P. \& Ukpere, W.I. (2020). Leadership styles and employees' demographic factors as predictors of work stress among bankers in south-west Nigeria, Journal of Psychology and Education, 57(8), 1125-1135.

2. Ahmed, Z., Rehman, Z.U., Asad, A., Hussain, N., \& Bilal, A. (2013). The impact of organisational change on the employee's performance in banking sector of Pakistan. Ethiopian International Journal of Multidisciplinary Research, 1(1), 1-12.

3. Allen, N.S. \& Herbert, A.S. (2002). Change as the winds change: the impact of organisational transformation on firm survival in a shifting environment. Organisational Analysis, 12(4), 361-377.

4. Almaraz, J. (1994). Quality management and the process of change. Journal of Organisational Change Management, 7(2), 06-14.

5. Anvari, M. (2007). Impact of information technology on human resources in healthcare, 10(4):84-88. Online resource at https://pubmed.ncbi.nlm.nih.gov/18027453/

6. Armenakis, A.A., \& Bedeian, A.G. (2001). Organisational change: a review of theory and research in the 1990s. Journal of Management, 25(3), 293-315.

7. Armenakis, A.A., Harris, S.G. \& Feild, H.S. (1999). Making change permanent: a model for institutionalising change interventions. In W.A. Pasmore \& R.W.Woodman (Eds.), Research in organisational change and development, 97-128, Oxford, England: JAI Press

8. Awadh, A.M. \& Saad, A.M. (2013). Impact of organisational culture on employee performance. International Review of Management and Business Research, 2.

9. Baca, N \& Claudia, D. (2005). Project managers spotlight on change management. Alameda: Sybex. Beeson.

10. Balogun, F. and Hailey, K. (2004). Transforming organisations, methods for accelerating culture change processes. Information Knowledge Systems Management, 1(2), 105-115.

11. Bass, B.M. (1985), Leadership and performance beyond expectations, Free Press, New York, NY

12. Burgelman, R.A. (1991). Intra-organisational ecology of strategy making and organisational adaptation: theory and field research. Organisational Science, 2, 239-262.

13. Burnes B. (2004). Managing change. London Pitman Publishing.

14. Cameron, S.K., \& Ouinn, E.R. (2011). Diagnosing and changing organisational culture: based on the competing values, AddisonWesley Publishing Company. 
15. Colgate, M., \& Hedge, R. (2001). An investigation into the switching process in retail banking services, International Journal of Bank Marketing 19(5), 201-212.

16. Connelly, M. (2017). Force field analysis. Online resource on https://www.change-management-coach.com/force-fieldanalysis.html.

17. Constantine, L., Ioannis, E.C., \& Magdalini, S. (2006). The importance of service quality in bank selection for mortgage loans. Journal of Service Theory and Practice. 16(4), 365-379.

18. Coppersmith, K. (2019). How technology improves workplace productivity, https://www.business2community.com/humanresources/

19. Costello, S.A. (2004). Culture and leadership, San Francisco: JosseyBass.

20. Denison, D. (2000). Corporate culture and organisational effectiveness. New York: Wiley.

21. Diener, E., \& Seligman, M. E. P. (2004). Beyond money: Toward an economy of wellbeing. Psychological Science in the Public Interest, 5, $1-31$.

22. Drucker, F. (2003). The practice of management. New York: Harper Business.

23. Ejuu, E. (2003). Building brand commitment: a behavioural approach to internal brand management. Journal of Brand Management, 12(4), 279-300.

24. Gliem, J.A. and Gliem, R.R. (2003), Calculating, Interpreting, and Reporting Cronbach's Alpha Reliability Coefficient for Likert-Type Scales, (A refereed paper presented at the Midwest Research to Practice Conference in Adult, Continuing, and Community Education).

25. Hirschhorn, L. (2000). Changing Structure is not enough: the moral meaning of organisational design. In M. Beer \& N. Nohria (Ed.), Breaking the code of change. Harvard Business School, Boston, Massachusetts, pp. 161-176.

26. Ho, L. (2008). What affects organisational performance? The linking of learning and knowledge management, Industrial Management and Data Systems, 108(9), 1234-1254.

27. Holt, D.T., Armenakis, A.A., Harris, S.G., \& Feild, H.S. (2007). Toward a comprehensive definition of readiness for change: a review of research and instrumentation. Research in Organisational Change and Development, 16, 289-336. 
28. House, R. J., Spangler, W. D., \& Woycke, J. (1991). Personality and charisma in the US presidency: A psychological theory of leader effectiveness. Administrative Science Quarterly, 364-396.

29. Irfan, A., Saira, A., Shahid, M., \& Umar, F. (2012). Determinant attributes of customer choice of Banks, supplying mortgage products, Journal of Economics and Behavioural Studies, 4(5), 287-296.

30. Isern, J. \& Pung, A. (2007). Harnessing energy to drive organisational change. McKinsey Quarterly, 16-19.

31. Kansal, K.K. \& Singh, A. (2016). Impact of organisation change on employees performance in Maruti Suzuki, International Journal of Research in IT and Management (Ijrim), 6(11), 16- 21.

32. Karanja, A.W. (2015). Organisational change and employee performance: a case on the postal corporation of Kenya. Change, $7(11)$.

33. Karatepe, O.M., Uludag, O., Menevis, I., Hadzimehmedagic, L., \& Baddar, L. (2006). The effects of selected individual characteristics on frontline employee performance and job satisfaction. Tourism Management, 27(4), 547-560.

34. Khan, M.M., \& Jabbar, M. (2013). Determinants of employees performance in corporate sector: case of an emerging market. Business and Management Research, 2(3), 25-32.

35. Khatoon, S. \& Farooq, A. (2016). Impact of organisational change on organisational performance. Global Journal of Management and Business Research. 16(3). 1-12.

36. Khosa1, Z.A., Rehman, Z.U., Asad, A., Bilal, M.A., \& Hussain, N. (2015). The impact of organisational change on the employee's performance in the Banking sector of Pakistan. Journal of Business and Management (IOSR). 17(3). 54-61.

37. Kim, J. (2018). The contrary effects of intrinsic and extrinsic motivations on burnout and turnover intention in the public sector, International Journal of Manpower, 39(3), 486-500.

38. Korir, J, and Mukolive, E. (2012). Organisational change Effects on Hotel CUL Change, BEH change, takeoversormance: Journal of social science tomorrow. 1(8).

39. Kotter, J.P. (1995). Leading change: why transformation efforts fail. Harvard Business Review, 59-67.

40. Kwizera, M., Olutayo, K.O., Irau, F., Wandiba, A., Abiria, P. \& Bayo, I. (2019). Effect of organisational change on employee performance among selected commercial banks in Bujumbura, Burundi. East African Scholars Journal of Economics, Business and Management, 2(4), 225-234. 
41. Laroche, M., Rosenblatt, J.A. \& Manning, T. (1986). The importance of service quality in bank selection for mortgage loans, International Journal of Bank Marketing, 4(1), 35-55.

42. Lewin, K. (1951). Field theory in social science. New York: Harper and Row.

43. Lin, W.T., \& Liu, Y. (2012). Successor characteristics, organisational slack, and change in the degree of firm internationalisation. International Business Review, 21(1), 89-101.

44. Lines, R. (2005). The structure and function of attitudes toward organisational change. Human Resource Development Review, 4(1), 832.

45. Martins, E.O. (2011). Organisational change in Nigerian firms: as risk sense making approach. Retrieved at http://moneyteachermatrix.blogspot.com on 14/04/2020.

46. Mento, A. J., Jones, R. M., \& Dirndorfer, W. (2002). A change management process: grounded in both theory and practice. Journal of Change Management, 3, 45-59.

47. Moran, J.W. \& Brighton, B.K. (2011). Leading organisational change, Career Development International, 6(2), 111-118.

48. Mullins, J.L. (2010). Management and organisational behaviour $\left(9^{\text {th }}\right.$ eds.). London Pearson.

49. Nwinyokpugi, P.N. (2018). Organisational change management and employees productivity in the Nigeria Banking sector, Journal of Business and Management (IOSR-JBM), 20(1), 11-20

50. Obondo, P.E. (2004). Internal market orientation: construct and consequences. Journal of Business Research, 57(40), 405-413.

51. Olajide, O.T. (2014). Change management and its effects on organisational performance of Nigerian Telecoms industries: empirical insight from Airtel Nigeria, International Journal of Humanities Social Sciences and Education (IJHSSE), 1(11), 170-179.

52. Omo, A. (2011). The determinants of Bank selection choices by customers: recent and extensive evidence from Nigeria, International Journal of Business and Social Science, 2(22), 276-288.

53. Peterson, K., \& McCleery, E. (2014). Evidence brief: the effectiveness of mandatory computer-based trainings on government ethics, workplace harassment, or privacy and information security-related topics. In: V.A. Evidence Synthesis Programme Evidence Briefs [Internet]. Washington (DC): Department of Veterans Affairs (US).

54. Phoung, H.T. \& Har, K.Y., (2000). A study of Bank selection decision in Singapore using the analytical hierarchy process. International Journal of Bank Marketing, 18(4), 170-180. 
55. Podsakoff, P.M., Mackenzie, S.B. \& Bommer, W.H. (1996). Transformational leader behaviours and substitutes for leadership as determinants of employee satisfaction, commitment, trust, and organisational citizenship behaviours, Journal of Management, 22, 259-98.

56. Rajagopalan, N., \& Spreitzer, G.M. (1996). Toward a theory of strategic change: a multi-lens perspective and integrative framework, Academy of Management Review, 22(1), 48-79.

57. Rezaei, M. Rezaei, M., Zare, M.. Akbarzadeh, H., \& Zare, F. (2014). The effects of information technology (IT) on employee productivity in Shahr Bank (Case study of Shiraz, Iran), Applied mathematics in Engineering, Management and Technology, The special issue in Management and Technology, 1208-1214.

58. Sashkin, M., \& Burke, W.W. (1987). Organisation development in the 1980s. Journal of Management, 13, 393-417.

59. Saunders, M., Lewis, P., \& Thornhill, A. (2007). Research methods for business students, $\left(4^{\text {th }}\right.$ edn.), Prentice Hall Ltd.

60. Schein, E. H. (2004). Organisational culture and leadership. (2nd. ed.). San Francisco: Jossey-Bass

61. Tavakolia, M. (2010). A positive approach to stress, resistance and organisational change. Social and Behavioural Sciences, 5, 17941798.

62. Tichy, N.M. \& Devanna, M.A. (1990), The transformational leader, John Wiley, New York, NY.

63. Ulengin, B. (1998). Using hierarchical information integration to examine customer preferences in banking. International Journal of Bank Marketing, 16, 202-210.

64. Wambugu, L.W. (2014). Effects of organisational culture on employee performance: a case study of Wartsila-Kipevu Ii power plant. European Journal of Business and Management, 6(32).

65. Wang, H., Law, K.S., Hackett, R.D., Wang, D., \& Chen, Z.X. (2005). Leader-member exchange as a mediator of the relationship between transformational leadership and followers' performance and organisational citizenship behaviour. Academy of Management Journal, 48, 420-432.

66. Wanza, L. \& Nkuraru, J.K. (2016). Influence of change management on employee performance: A case of University of Eldoret, Kenya, International Journal of Business and Social Science, 7(4), 190-199.

67. Warren, G.B., Kenneth, D.B., \& Robert, C. (2009). The planning of change. (2nd Edition). Holt, Rinehart and Winston, New York. 
68. Webb, K. (2007). Motivating peak performance: leadership behaviours that stimulate employee motivation and performance. Texas Women's University, 6, 53-71.

69. Westbrook, J.I., Braithwaite, J., Gibson, K., Paoloni, R., Callen, J., Georgiou, A., Creswick, N., \& Robertson, L. (2009). Use of information and communication technologies to support effective work practice innovation in the health sector: a multi-site study, $B M C$ Health Services Research, 9(201), https://doi.org/10.1186/1472-69639-201.

70. Zineldin, M. (2005). Research and concepts quality and customer relationship management (CRM) as competitive strategy in the Swedish banking industry. The TQM Magazine, 17(4), 329-344. 